\title{
(6) OPEN ACCESS \\ Tobacco price increase and smoking behaviour changes in various subgroups: a nationwide longitudinal 7-year follow-up study among a middle-aged Japanese population
}

\author{
Takahiro Tabuchi, ${ }^{1}$ Takeo Fujiwara, ${ }^{2}$ Tomohiro Shinozaki $^{3}$
}

- Additional material is published online only. To view please visit the journal online (http://dx.doi.org/10.1136/ tobaccocontrol-2015-052804).

${ }^{1}$ Center for Cancer Control and Statistics, Osaka Medical Center for Cancer and Cardiovascular Diseases, Osaka, Japan

${ }^{2}$ Department of Social Medicine, National Research Institute for Child Health and Development, Tokyo, Japan ${ }^{3}$ Department of Biostatistics, School of Public Health, The University of Tokyo, Tokyo, Japan

\section{Correspondence to} Dr Takahiro Tabuchi, Center for Cancer Control and Statistics, Osaka Medical Center for Cancer and Cardiovascular Diseases, 3-3-1, Nakamichi, Higashinari-ku, Osaka 537-8511, Japan; tabuchitak@gmail.com

Received 1 November 2015 Accepted 27 January 2016 Published Online First 15 February 2016

\begin{abstract}
Objective Few longitudinal studies have examined the effect of tobacco price increase on both cessation among smokers and relapse among quitters. Our objective was to investigate the differential impact of the tobacco price increase on the changes in smoking status in the total population and various subgroups.

Methods We analysed data from a Japanese nationally representative longitudinal study of 30773 individuals aged $50-59$ years (weighted sum of discrete-time number $=215411$ ) with smoking information, using inverse probability weighting to account for nonresponse at follow-up. Generalised estimating equation models were used to calculate the odds ratios (ORs) for smoking behavioural changes (cessation among smokers and relapse among quitters), using discrete-time design. Stratified analyses were conducted according to demographic, socioeconomic and health behavioural characteristics.
\end{abstract}

Results From 2005 to 2012, current smoker prevalence among the middle-aged Japanese population decreased from $30.5 \%$ to $24.3 \%$. Of all the factors surveyed, only the tobacco price increase in 2010 (up by $37 \%$, the highest increase during the period) was significantly associated with both cessation among smokers (OR 2.14, 95\% confidence interval 1.90 to $2.41)$ and prevention of relapse among quitters $(0.60$, 0.46 to 0.77 ). Regarding the subgroup analysis, the tobacco price increase was associated with a significant reduction in relapse in the lowest income, recent quitters and very poor health subgroups. However, different associations were observed for cessation; a significant association between price increase and cessation was observed among all subgroups except for the heavy smoker and recently unemployed subgroups.

Conclusions We confirmed that the tobacco price rise was associated with increasing cessation and decreasing relapse concurrently. Furthermore, this price rise was associated with favourable smoking changes in nearly all population subgroups; a large differential impact was not observed across the various subgroups.

\section{INTRODUCTION}

CrossMark

To cite: Tabuchi T, Fujiwara T, Shinozaki T. Tob Control 2017;26:69-77.
Increases in tobacco excise tax that result in higher tobacco prices are considered best practice to reduce population tobacco use and inherent smoking inequality. ${ }^{1}{ }^{2}$ A longitudinal study design is appropriate to estimate the effects of a price increase. ${ }^{3}$ Since few previous studies focused on the impact of price increase on relapse, longitudinal studies which provide evidence of the effect of tobacco price on both cessation among smokers and relapse among quitters are scarce. ${ }^{14-7}$ In addition, the impact of tobacco price increases on smoking behaviour in different social groups has been investigated; mixed results have been reported for differences in gender, occupation and education subgroups. ${ }^{8-10}$ Generally, increases in tobacco price reduce cigarette use, especially among the poor and the young rather than the affluent and the old. ${ }^{1}$ The impact of tobacco price increases is of great interest to the public health community because they play a pivotal role in people's decisions to use tobacco. $^{2}$ In Japan, a special tobacco tax was imposed on 1 December 1998 and the real price of tobacco increased on 1 July 2003, 1 July 2006, 1 October 2010 and 1 April 2014. The price of a pack ( 20 cigarettes) of the most popular brand in Japan, Mild Seven (the brand name was changed to 'Mevius' in 2013), increased from 250 to 270 yen ( $8 \%$ increase) in 2003 , to 300 yen (11\% increase) in 2006 , to 410 yen ( $37 \%$ increase) in 2010 , and to 430 yen $\left(5 \%\right.$ increase) in $2014 .{ }^{11}$ Partly owing to these price increases, current smoking prevalence among Japanese adults (both sexes) aged 20 years or more has decreased from $31 \%$ in 2001 to $22 \%$ in $2013 .^{12}$

Furthermore, most studies did not account for attrition at follow-up in the analyses. ${ }^{1}$ Therefore, we used data collected between 2005 and 2012 from a nationally representative middle-aged population in Japan and investigated trajectories of smoking status and determinants of important smoking behavioural changes (ie, cessation and relapse), and the association between the tobacco price increase and smoking changes, accounting for attrition at follow-up. Our objective was to reveal the differential impact of the tobacco price increase on the changes in smoking status in the total population and various subgroups, such as socioeconomic, work, smoking or health status in Japan.

\section{METHODS}

Data

We used data from the Longitudinal Survey of Middle-aged and Elderly Persons, a nationally representative study conducted by the Ministry of Health, Labour and Welfare (MHLW). ${ }^{13-15}$ The study participants, who were aged 50-59 years on 31 October 2005, were selected by two-stage random sampling, and were followed up every year via face-to-face survey (1st-5th year) and mailed 
survey (6th-8th year). Of 5280 districts selected for the nationwide population-based cross-sectional survey in $2004,{ }^{12} 2515$ districts were randomly selected. Within the districts, 40877 residents aged 50-59 years were surveyed on 2 November 2005. A total of 33815 individuals responded, giving a response rate of $82.7 \%$. The second to eighth waves of the survey were conducted in November 2006-2012 and consisted of 31 403, 30 013, 28 945, 28 151, 25 740, 24879 and 23614 respondents, respectively (the retention rate during the period 2005-2012 was 69.8\%). We obtained permission from MHLW to use the data. The analyses of national survey data were considered to be exempt from the need for ethical review according to the Epidemiological Research Guidelines.

\section{Smoking behaviours and the changes}

Smoking status was classified as never-smoker, quitter or current smoker based on the question 'Do you smoke now?' with possible responses of 'I have never smoked'; 'I have stopped smoking'; or 'I smoke now'. Smoking status was followed up every year with the question 'Do you smoke now?' with possible responses of 'I do not smoke now' or 'I smoke now'. According to these responses, smoking status at the time of survey was determined to be never-smoker, quitter or current smoker. For current smokers, the number of cigarettes per day was determined by asking: 'how many cigarettes do you usually smoke a day?'. Response categories were 1-10, 11-20, 21-30 and 31 or more per day. 'Recent quitter' was defined as someone who had stopped smoking within the last year.

Usually individuals move in and out of different smoking status categories over time. We evaluated smoking behavioural changes between consecutive waves: each baseline and the next follow-up in discrete-time design, that is, all variations of the $k$ th to the $(k+1)$ th waves, for $k=1, \ldots, 7$. Smoking cessation at the $(k+1)$ th wave was identified as a current smoker at the time of the baseline survey ( $k$ th wave) who had become a quitter at the time of the next survey (ie, $(k+1)$ th wave). Relapse at the $(\mathrm{k}+1)$ th wave was defined as a quitter at the time of the baseline kth survey who had become a current smoker at the time of the $(k+1)$ th survey. Note that in our discrete-time design, the risk set for cessation at the $(k+1)$ th wave comprised those who were classified as current smokers at the kth wave. In the same way, the risk set for relapse at the $(k+1)$ th wave comprised those who were classified as quitters at the kth wave. Thus, participants who initiated cessation during the follow-up period entered the risk set for relapse thenceforth; likewise, participants who restarted smoking entered the risk set for cessation thenceforth. This approach allowed us to treat multiple events (multiple cessation/relapse) among the same participants.

\section{Variables}

A broad set of covariates, which could be associated with smoking behaviour, included: (1) sex, (2) age (50-54, 55-59 or 60-65 years), (3) education (junior high school, high school, technical school or junior college, or university (4 years) or more), (4) marital status (married, divorced/widowed, or never married), (5) equivalent household income (quintiles), (6) housing tenure (not owning housing or owning housing), (7) working condition (working, unemployed or other (eg, retired or housewife)), (8) self-rated health (excellent, good, poor or very poor) and (9) alcohol consumption (everyday drinker, 1-6 times/week drinker, 1-3 times/month drinker, seldom drinker or never drinker). Equivalent household income was calculated by combining income reported by a respondent and his/her spouse and dividing the sum of the income by the square root of the number of family members, in order to adjust for household size,${ }^{16}$ and was categorised by quintile. We divided working condition into four categories: working, retired/homemaker/other, recently unemployed (within 1 year) or other unemployment (including unknown date for the start of unemployment). Those not working were categorised as unemployed if they were seeking employment; otherwise, they were considered economically inactive (eg, retired or homemaker).

\section{Statistical analyses}

The longitudinal approach is suited to the study of changes in smoking behaviour over time. However, a high percentage of the participants will be lost to follow-up. ${ }^{17}$ If those lost differ in important respects to those who remain in the study, the results can be biased. ${ }^{3}$ To account for the non-random non-response, we used inverse probability weighting (IPW) for the remaining participants in each survey by modelling the probability of not dropping out from the study (details are shown in the online supplementary data). ${ }^{18}$ The unweighted available data analyses are presented in the online supplementary data.

The $\chi^{2}$ tests were used to compare the difference in smoking status according to characteristic variables. Using the discretetime design, where each wave of participants was treated as an analytical unit, the IPW logistic generalised estimating equation (GEE) model was used to calculate the adjusted odds ratios (AORs) and 95\% confidence intervals (CIs) for smoking behavioural changes (cessation and relapse) from the kth to $(k+1)$ th waves during the follow-up interval $(k=1, \ldots, 7)$. The dependence of observations that belong to the same individual due to the discrete-time design that allows multiple events, and the IPW were accounted for by sandwich variance estimators assuming an unstructured correlation matrix within the same individual. ${ }^{19}$ Since the tobacco price increased on 1 July 2006 and 1 October 2010 during the study period, the periods 2005-2006 and 2009-2010 (a year from November to November) were interpreted as a proxy variable for tobacco price increase. The period 2005-2006 was not analysed for relapse because we had no data in the recent quitter variable. Furthermore, the range of the price increase was larger in 2010 than in 2006. Thus, we mainly focused on the 2010 tobacco price increase. The last period (2008-2009) before the period of the 2010 price increase was used as a reference category. To examine the differential impact of the 2010 tobacco price increase in various subgroups, GEE was separately conducted in each subgroup (stratified analysis). Furthermore, to confirm the interaction effect between the 2010 tobacco price increase (period 20092010) and each subgroup, we also conducted GEE using an interaction term (see online supplementary data) to estimate the AORs between subgroups. The trend association was assessed by linear trend for covariate category, treated as an ordinal variable. Trend analyses for the period variable were used to observe hardening or softening ${ }^{20}$ in smokers over time. Participants with a missing value for any baseline characteristic (except income) were excluded from the IPW-GEE analyses.

Probability values for statistical tests were two-tailed and $\mathrm{p}<0.05$ was considered statistically significant. All analyses were performed using SAS V.9.2 (SAS Institute, Cary, North Carolina, USA).

\section{RESULTS}

Of 31403 individuals who responded to both the first and second surveys, we excluded those with missing smoking information $(n=630)$, and analysed the remaining 30773 individuals 
(total number of discrete-time person-years $=215411$ ) using IPW accounting for non-response.

The distribution of smoking at each wave, and the changes between waves, are shown in table 1 . In the first survey, $30.5 \%$ were current smokers, reducing to $24.3 \%$ in the eighth survey among respondents with IPW adjustments for non-response, although those decreased to $19.5 \%$ when we used only available respondents (unweighted; see online supplementary table S1). Around 3-9\% of participants either relapsed or stopped smoking between waves-with slightly more stopping, leading to a reduction in smoking prevalence over time. Following the large tobacco price increase between the fifth and sixth surveys, more stopping and less relapsing were observed during 20092010 than during other periods.

The distribution of covariates among total baseline participants (total number of discrete-time person-years) is shown in online supplementary table S2. The rates of current smokers and quitters were significantly different according to all the baseline characteristics such as sex, age, education and marital status. The results from the unweighted available data analyses did not differ largely (see online supplementary table S3).

OR for cessation according to baseline characteristics among current smokers are shown in table 2. After excluding participants with missing variable information $(n=6562), 52699$ current smokers (weighted number) were analysed by GEE. Cessation rates during the periods '2005-2006' (OR 1.29, 95\% CI 1.13 to 1.46), '2007-2008' (OR 1.20, 95\% CI 1.06 to 1.36) and '20092010' (OR 2.14, 95\% CI 1.90 to 2.41) were significantly higher than the rate during the period '2008-2009'. Further, lower numbers of cigarettes smoked per day, older age groups, being married, owning housing, recent unemployment and lower alcohol consumption (including never drinkers) were significantly associated with cessation compared with the reference categories.

Rates of cessation in various subgroups were compared between the period '2008-2009' and '2009-2010' and are shown in figure 1 . Among all subgroups, a significant impact on cessation was observed during the period '2009-2010' except in two subgroups: 31 or more cigarettes smoked per day and recent unemployment.

ORs for relapse according to baseline characteristics among quitters are shown in table 3. After excluding participants with missing variable information $(n=5132), 51491$ quitters (weighted number) were analysed for GEE. Since information for recent quitting was not available in the first survey, discrete time for the period 2005-2006 was not used for relapse $(n=6493)$. The relapse rate for '2009-2010' is significantly lower than the rate for '2008-2009' (OR 0.60, 95\% CI 0.46 to 0.77). Furthermore, sex, recent quitter, higher household income, and very poor self-rated health were significantly associated with relapsed smoking compared with reference categories. A significant $\mathrm{p}$ for trend confirmed the results for household income and self-rated health.

Rates of relapse in various subgroups compared between '2008-2009' and '2009-2010' are shown in figure 2. A significant impact on relapse reduction during the period '20092010' was observed in many subgroups, that is, both sexes, recent quitter, older age groups, technical school or junior college education, married and never married status, lowest household income, owning housing, unemployed categories, very poor self-rated health, and seldom or never drinkers. The results from the unweighted available data analyses for cessation and relapse showed similar estimates with few differences in significance (see online supplementary tables S4 and S5 and figures S1 and S2).

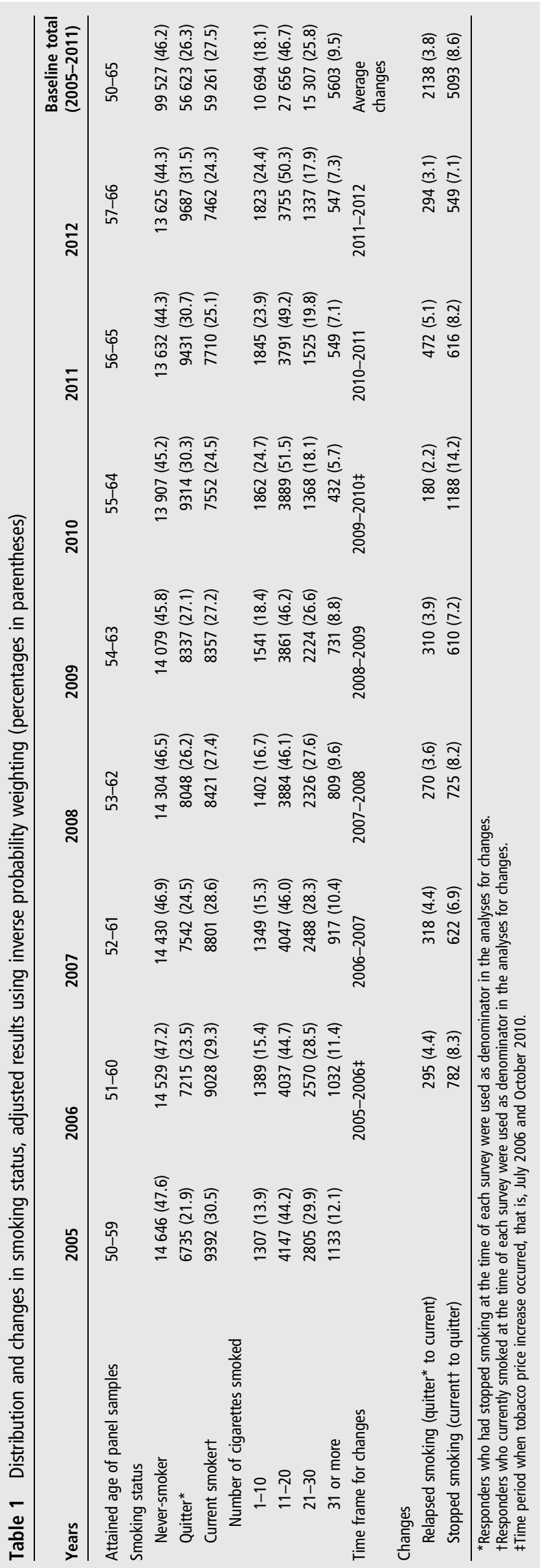


Table 2 OR for short-term cessation

\begin{tabular}{|c|c|c|c|c|c|}
\hline Characteristics & Number of smokers & $\begin{array}{l}\text { Number of smokers } \\
\text { who quitted }\end{array}$ & Per cent & Adjusted OR* $(95 \% \mathrm{CI})$ & $p$ for trend \\
\hline Duration & & & & & 0.945 \\
\hline 2005-2006t & 8964 & 744 & 8.3 & $1.29(1.13$ to 1.46$)$ & \\
\hline 2006-2007 & 8577 & 599 & 7.0 & $1.01(0.89$ to 1.15$)$ & \\
\hline 2007-2008 & 8088 & 673 & 8.3 & $1.20(1.06$ to 1.36$)$ & \\
\hline 2008-2009 & 7487 & 532 & 7.1 & 1 (reference) & \\
\hline 2009-2010† & 7171 & 1025 & 14.3 & 2.14 (1.90 to 2.41$)$ & \\
\hline 2010-2011 & 6311 & 571 & 9.1 & $1.18(0.92$ to 1.50$)$ & \\
\hline 2011-2012 & 6101 & 443 & 7.3 & 0.91 (0.76 to 1.09$)$ & \\
\hline \multicolumn{6}{|l|}{ Sex } \\
\hline Men & 41245 & 3398 & 8.2 & 1 (reference) & \\
\hline Women & 11455 & 1188 & 10.4 & $1.03(0.91$ to 1.16$)$ & \\
\hline Number of cigarettes smoked per day & & & & & $<0.001$ \\
\hline $1-10$ & 9251 & 1454 & 15.7 & 3.09 (2.62 to 3.64$)$ & \\
\hline $11-20$ & 24585 & 1956 & 8.0 & 1.49 (1.28 to 1.73$)$ & \\
\hline $21-30$ & 13846 & 897 & 6.5 & 1.18 (1.01 to 1.37$)$ & \\
\hline 31 or more & 5017 & 280 & 5.6 & 1 (reference) & \\
\hline Age (years) & & & & & $<0.001$ \\
\hline $50-54$ & 11934 & 888 & 7.4 & 1 (reference) & \\
\hline $55-59$ & 27007 & 2301 & 8.5 & $1.12(1.02$ to 1.23$)$ & \\
\hline $60-65$ & 13759 & 1397 & 10.2 & $1.32(1.13$ to 1.54$)$ & \\
\hline Education & & & & & 0.656 \\
\hline Junior high school & 12632 & 1076 & 8.5 & 1 (reference) & \\
\hline High school & 25653 & 2225 & 8.7 & $1.04(0.90$ to 1.20$)$ & \\
\hline Technical school or junior college & 5786 & 514 & 8.9 & $1.00(0.84$ to 1.19$)$ & \\
\hline University (4 years) or more & 8630 & 771 & 8.9 & $1.05(0.90$ to 1.23$)$ & \\
\hline \multicolumn{6}{|l|}{ Marital status } \\
\hline Married & 42804 & 3955 & 9.2 & $1.56(1.25$ to 1.95$)$ & \\
\hline Divorced/widowed & 6002 & 414 & 6.9 & $1.09(0.85$ to 1.40$)$ & \\
\hline Never married & 3893 & 217 & 5.6 & 1 (reference) & \\
\hline Equivalent household income & & & & & 0.123 \\
\hline 1st quintile (lowest) & 9483 & 849 & 9.0 & 1 (reference) & \\
\hline 2nd quintile & 8562 & 699 & 8.2 & $0.90(0.74$ to 1.11$)$ & \\
\hline 3rd quintile & 8689 & 728 & 8.4 & $0.97(0.79$ to 1.19$)$ & \\
\hline 4th quintile & 8222 & 677 & 8.2 & $0.98(0.80$ to 1.20$)$ & \\
\hline 5th quintile (highest) & 8004 & 765 & 9.6 & $1.14(0.93$ to 1.39$)$ & \\
\hline Did not answer/missing & 9739 & 869 & 8.9 & $0.92(0.75$ to 1.14$)$ & \\
\hline \multicolumn{6}{|l|}{ Housing tenure } \\
\hline Does not own housing & 11212 & 779 & 7.0 & 1 (reference) & \\
\hline Owns housing & 41488 & 3807 & 9.2 & $1.26(1.05$ to 1.50$)$ & \\
\hline \multicolumn{6}{|l|}{ Working condition } \\
\hline Working & 43425 & 3645 & 8.4 & 1 (reference) & \\
\hline Retired/homemaker/other & 4320 & 457 & 10.6 & 1.11 (0.94 to 1.32$)$ & \\
\hline Recently unemployed (within 1 year) & 1524 & 202 & 13.3 & $1.45(1.10$ to 1.92$)$ & \\
\hline Other unemployed (including unknown date) & 3430 & 282 & 8.2 & $0.91(0.70$ to 1.19$)$ & \\
\hline Self-rated health & & & & & 0.231 \\
\hline Excellent & 18135 & 1551 & 8.6 & 1 (reference) & \\
\hline Good & 22658 & 1996 & 8.8 & $1.07(0.99$ to 1.16$)$ & \\
\hline Poor & 8952 & 720 & 8.0 & $1.01(0.85$ to 1.19$)$ & \\
\hline Very poor & 2955 & 320 & 10.8 & $1.21(0.94$ to 1.57$)$ & \\
\hline \multicolumn{6}{|l|}{ Alcohol consumption } \\
\hline Everyday drinker & 21238 & 1715 & 8.1 & 1 (reference) & \\
\hline 1-6 times per week drinker & 11172 & 949 & 8.5 & $1.01(0.90$ to 1.14$)$ & \\
\hline 1-3 times per month drinker & 2515 & 260 & 10.3 & $1.29(1.09$ to 1.53$)$ & \\
\hline Seldom drinker & 7840 & 728 & 9.3 & 1.12 (0.99 to 1.28$)$ & \\
\hline Never drinker & 9934 & 934 & 9.4 & $1.16(1.00$ to 1.34$)$ & \\
\hline
\end{tabular}

Discrete-time cohorts; generalised estimating equation (GEE) analyses with weighting.

Bold indicates statistical significance of $p<0.05$.

*Adjusted for all listed variables.

tTobacco price increases occurred at 1 July 2006 and 1 October 2010. 


\begin{tabular}{|c|c|c|c|c|}
\hline \multirow[b]{2}{*}{ Subgroups } & \multirow{2}{*}{$\frac{2008-2009}{\%}$} & \multicolumn{3}{|c|}{$2009-2010^{*}$} \\
\hline & & $\%$ & Adj & \\
\hline \multicolumn{5}{|l|}{ Sex } \\
\hline Men & 6.7 & 13.8 & & $2.16(1.87-2.51)$ \\
\hline Women & 8.6 & 16.0 & & $2.04(1.59-2.62)$ \\
\hline \multicolumn{5}{|l|}{ Number of cigarettes smoked per day } \\
\hline $1-10$ & 13.0 & 24.7 & & $2.17(1.70-2.77)$ \\
\hline $11-20$ & 6.1 & 13.6 & & $2.39(1.97-2.89)$ \\
\hline $21-30$ & 6.0 & 10.9 & & $1.89(1.45-2.45)$ \\
\hline 31 or more & 5.2 & 8.0 & & $1.45(0.89-2.37)$ \\
\hline \multicolumn{5}{|l|}{ Age (years) } \\
\hline $50-54$ & 6.4 & 11.7 & & $1.93(1.34-2.79)$ \\
\hline $55-59$ & 6.7 & 13.8 & & $2.25(1.89-2.69)$ \\
\hline $60-65$ & 8.4 & 15.6 & & $2.07(1.67-2.55)$ \\
\hline \multicolumn{5}{|l|}{ Education } \\
\hline Junior high school & 6.2 & 14.4 & & $2.52(1.90-3.36)$ \\
\hline High school & 6.8 & 14.1 & & $2.17(1.81-2.60)$ \\
\hline Technical school or junior college & 9.2 & 14.7 & & $1.70(1.20-2.41)$ \\
\hline University (4-years) or more & 8.0 & 14.7 & & $1.94(1.45-2.60)$ \\
\hline \multicolumn{5}{|l|}{ Marital status } \\
\hline Married & 7.5 & 15.2 & & $2.14(1.87-2.45)$ \\
\hline Divorced/widowed & 5.9 & 10.9 & & $1.97(1.26-3.10)$ \\
\hline Never married & 4.4 & 9.6 & & $2.31(1.26-4.26)$ \\
\hline \multicolumn{5}{|l|}{ Equivalent household income } \\
\hline 1st quintile (lowest) & 7.7 & 14.3 & & $1.98(1.47-2.65)$ \\
\hline 2nd quintile & 6.6 & 14.0 & & $2.27(1.62-3.17)$ \\
\hline 3rd quintile & 7.6 & 15.1 & & $2.13(1.52-2.96)$ \\
\hline 4th quintile & 6.4 & 16.1 & & $2.67(1.86-3.82)$ \\
\hline 5th quintile (highest) & 8.4 & 12.7 & & $1.63(1.16-2.30)$ \\
\hline \multicolumn{5}{|l|}{ Housing tenure } \\
\hline Does not own housing & 4.6 & 11.8 & & $2.97(2.08-4.24)$ \\
\hline Owns housing & 7.7 & 14.9 & $\rightarrow$ & $2.01(1.76-2.31)$ \\
\hline \multicolumn{5}{|l|}{ Working condition } \\
\hline Working & 6.7 & 13.8 & 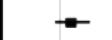 & $2.19(1.90-2.52)$ \\
\hline Retired/homemaker/other & 10.1 & 17.0 & $\rightarrow$ & $1.90(1.26-2.84)$ \\
\hline Recently unemployed & 11.1 & 16.9 & & $1.59(0.87-2.92)$ \\
\hline Other unemployed & 7.1 & 14.3 & & $2.28(1.25-4.13)$ \\
\hline \multicolumn{5}{|l|}{ Self-rated health } \\
\hline Excellent & 7.3 & 14.9 & $\rightarrow-$ & $2.19(1.78-2.69)$ \\
\hline Good & 7.3 & 14.5 & $\rightarrow$ & $2.11(1.75-2.54)$ \\
\hline Poor & 6.5 & 12.7 & $\longrightarrow$ & $1.96(1.41-2.73)$ \\
\hline Very poor & 5.6 & 14.2 & & $3.13(1.61-6.11)$ \\
\hline \multicolumn{5}{|l|}{ Alcohol consumption } \\
\hline Everyday drinker & 6.2 & 13.2 & & $2.28(1.85-2.82)$ \\
\hline 1-6 times per week drinker & 7.7 & 13.1 & $\rightarrow-$ & $1.77(1.35-2.32)$ \\
\hline 1-3 times per month drinker & 8.2 & 18.0 & & $2.33(1.33-4.06)$ \\
\hline Seldom drinker & 7.0 & 16.2 & $\rightarrow$ & $2.52(1.83-3.48)$ \\
\hline Never drinker & 8.1 & 15.5 & $\rightarrow-$ & $2.04(1.54-2.70)$ \\
\hline
\end{tabular}

Figure 1 Rates of smoking cessation in various subgroups during 2008-2009 and 2009-2010. GEE analyses with weighting.

\section{DISCUSSION}

We examined the association between a tobacco price increase and both cessation among smokers and relapse among quitters, using a large longitudinal data set, and accounting for attrition. ${ }^{1}$ In the current study, from 2005 to 2012, current smoker prevalence among the middle-aged Japanese population decreased from $30.5 \%$ to $24.3 \%$ using IPW, partly due to tobacco price increases in 2006 and 2010. Since there is a higher attrition tendency among smokers than never-smokers, available data analysis would have resulted in a biased estimate (see online supplementary table S1). We therefore considered that IPW adjustments for non-responses might provide an appropriate figure of smoking prevalence.

\section{Impact of tobacco price increase}

Of all the factors surveyed, only the period 2009-2010 (when the $37 \%$ price increase occurred) was significantly associated with both promoting cessation among smokers and preventing relapse among quitters (tables 2 and 3). There are no local level variations in tobacco prices in Japan and the regulated increased price was applied throughout the country under the Tobacco Business Law ${ }^{21}$ (ie, there was no time delay in the market price rise across Japan). We could therefore assume that all study participants were equally affected by the increase. The tobacco price was increased on 1 October 2010, at least 1 month before the survey in November 2010, but there may have been an earlier response due to anticipation effects, ${ }^{22}$ as also seen in a 
Table 3 OR for relapse

\begin{tabular}{|c|c|c|c|c|c|}
\hline Characteristics & Number of ex-smoker & $\begin{array}{l}\text { Number of smoker } \\
\text { who relapsed }\end{array}$ & Per cent & $\begin{array}{l}\text { Adjusted } \\
\mathrm{OR}^{*}(95 \% \mathrm{Cl})\end{array}$ & $p$ for trend \\
\hline Duration & & & & & 0.295 \\
\hline 2006-2007 & 6933 & 304 & 4.4 & $1.13(0.92$ to 1.38$)$ & \\
\hline 2007-2008 & 7067 & 237 & 3.4 & $0.96(0.77$ to 1.18$)$ & \\
\hline 2008-2009 & 7365 & 275 & 3.7 & 1 (reference) & \\
\hline 2009-2010† & 7441 & 158 & 2.1 & $0.60(0.46$ to 0.77$)$ & \\
\hline 2010-2011 & 8145 & 399 & 4.9 & $1.06(0.81$ to 1.39$)$ & \\
\hline 2011-2012 & 8046 & 248 & 3.1 & $0.93(0.66$ to 1.31$)$ & \\
\hline \multicolumn{6}{|l|}{ Sex } \\
\hline Men & 35471 & 1094 & 3.1 & 1 (reference) & \\
\hline Women & 9527 & 528 & 5.5 & $1.39(1.13$ to 1.71$)$ & \\
\hline \multicolumn{6}{|l|}{ Recent quitter (within 1 year) } \\
\hline No & 40999 & 639 & 1.6 & 1 (reference) & \\
\hline Yes & 3999 & 982 & 24.6 & 17.9 (14.6 to 22.0$)$ & \\
\hline Age (years) & & & & & 0.884 \\
\hline $50-54$ & 6000 & 224 & 3.7 & 1 (reference) & \\
\hline $55-59$ & 21538 & 738 & 3.4 & $0.97(0.81$ to 1.17$)$ & \\
\hline $60-65$ & 17460 & 659 & 3.8 & $1.10(0.85$ to 1.41$)$ & \\
\hline Education & & & & & 0.637 \\
\hline Junior high school & 7889 & 352 & 4.5 & 1 (reference) & \\
\hline High school & 20435 & 762 & 3.7 & $0.98(0.77$ to 1.26$)$ & \\
\hline Technical school or junior college & 5507 & 242 & 4.4 & $1.17(0.81$ to 1.71$)$ & \\
\hline University (4 years) or more & 11168 & 266 & 2.4 & $0.88(0.67$ to 1.14$)$ & \\
\hline \multicolumn{6}{|l|}{ Marital status } \\
\hline Married & 39206 & 1321 & 3.4 & $0.73(0.45$ to 1.20$)$ & \\
\hline Divorced/widowed & 3599 & 200 & 5.6 & 0.87 (0.49 to 1.56$)$ & \\
\hline Never married & 2193 & 99 & 4.5 & 1 (reference) & \\
\hline Equivalent household income & & & & & 0.017 \\
\hline 1st quintile (lowest) & 6514 & 359 & 5.5 & 1 (reference) & \\
\hline 2nd quintile & 6986 & 254 & 3.6 & $0.80(0.61$ to 1.06$)$ & \\
\hline 3rd quintile & 7047 & 242 & 3.4 & $0.80(0.61$ to 1.03$)$ & \\
\hline 4th quintile & 7481 & 221 & 3.0 & $0.77(0.59$ to 0.99$)$ & \\
\hline 5th quintile (highest) & 8037 & 235 & 2.9 & $0.75(0.58$ to 0.98$)$ & \\
\hline Did not answer/missing & 8934 & 311 & 3.5 & 0.77 (0.56 to 1.07$)$ & \\
\hline \multicolumn{6}{|l|}{ Housing tenure } \\
\hline Does not own housing & 5740 & 285 & 5.0 & 1 (reference) & \\
\hline Owns housing & 39258 & 1336 & 3.4 & $0.86(0.65$ to 1.14$)$ & \\
\hline \multicolumn{6}{|l|}{ Working condition } \\
\hline Working & 36176 & 1176 & 3.3 & 1 (reference) & \\
\hline Retired/homemaker/other & 4873 & 219 & 4.5 & $1.00(0.73$ to 1.38$)$ & \\
\hline Recently unemployed (within 1 year) & 1505 & 79 & 5.3 & 1.17 (0.62 to 2.20$)$ & \\
\hline Other unemployed (including unknown date) & 2443 & 148 & 6.1 & $1.28(0.86$ to 1.91$)$ & \\
\hline Self-rated health & & & & & 0.016 \\
\hline Excellent & 16525 & 502 & 3.0 & 1 (reference) & \\
\hline Good & 18676 & 627 & 3.4 & $1.07(0.92$ to 1.24$)$ & \\
\hline Poor & 7346 & 318 & 4.3 & $1.19(0.92$ to 1.52$)$ & \\
\hline Very poor & 2450 & 174 & 7.1 & 1.55 (1.04 to 2.32$)$ & \\
\hline \multicolumn{6}{|l|}{ Alcohol consumption } \\
\hline Everyday drinker & 15239 & 470 & 3.1 & 1 (reference) & \\
\hline 1-6 times per week drinker & 11993 & 368 & 3.1 & $1.06(0.87$ to 1.29$)$ & \\
\hline $1-3$ times per month drinker & 2508 & 81 & 3.2 & 1.06 (0.78 to 1.44$)$ & \\
\hline Seldom drinker & 6605 & 270 & 4.1 & $1.01(0.83$ to 1.24$)$ & \\
\hline Never drinker & 8653 & 433 & 5.0 & 1.04 (0.83 to 1.30$)$ & \\
\hline
\end{tabular}




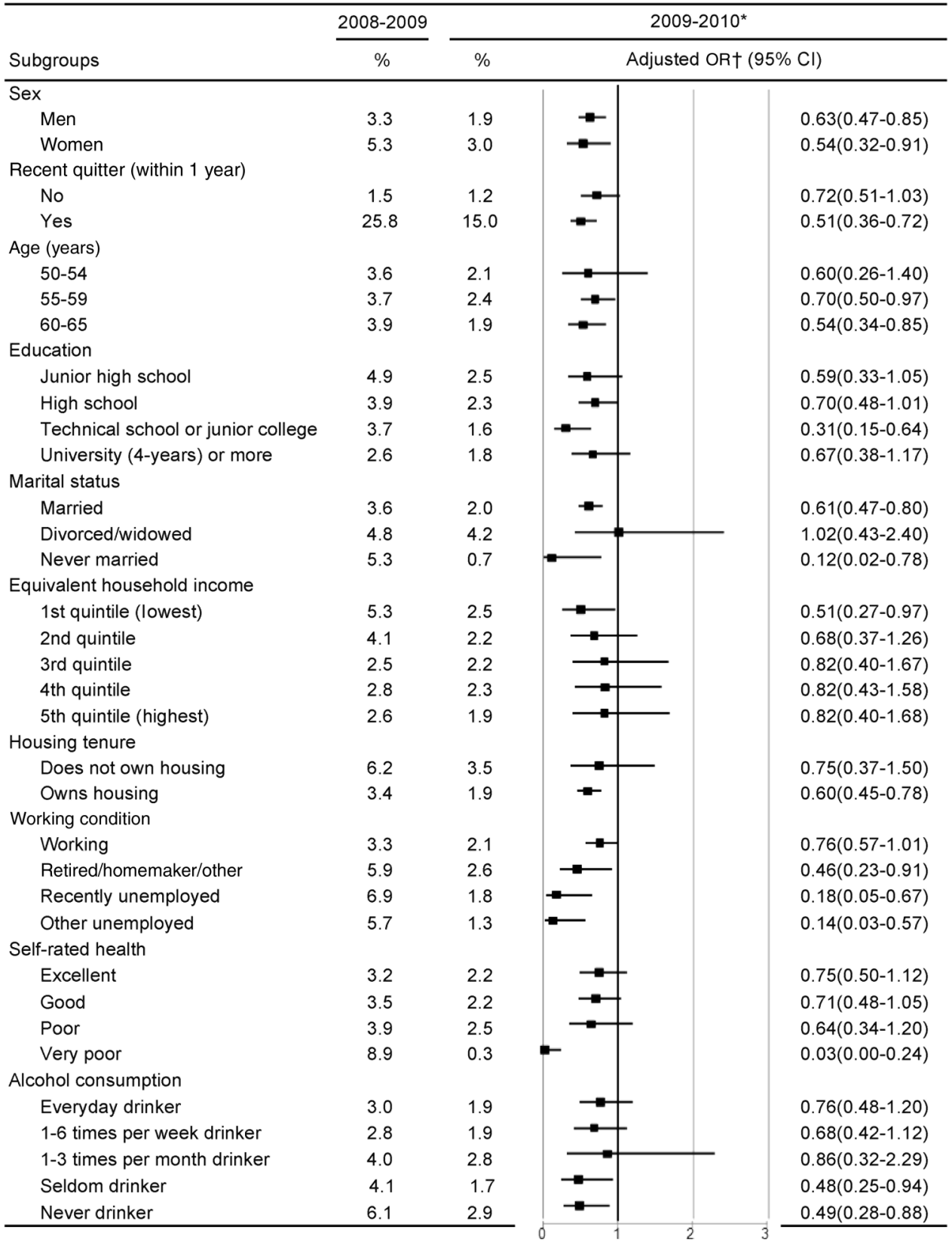

* Tobacco price increase occurred on 1 October 2010. Duration of 2008-2009 was used as a reference category. † Adjusted for all listed variables.

Figure 2 Rates of smoking relapse in various subgroups during 2008-2009 and 2009-2010. GEE analyses with weighting.

previous study. ${ }^{23}$ Another Japanese study has shown that intention to quit among smokers immediately before the tax increase (August-September 2010) was high, ${ }^{24}$ as $53 \%$ and $72 \%$ of those who intended to quit were planning this for 'before' or 'on' the day of the tax increase. Furthermore, no other major tobacco control measures were taken during the period 20092010 in $\mathrm{Japan}^{21}$; thus, cessation during this period, compared with 2008-2009 (as a reference), could be assumed to be the effect of the tobacco price.

Additionally, the rate of cessation during the periods 20052006 and 2007-2008 was significantly higher (for quitting only) compared with that during 2008-2009. There was an $11 \%$ price increase in 2005-2006. The smoking-cessation agent varenicline has been covered by insurance providers since April
$2008^{25}$ and electronic locking devices utilising verification cards have been mandated since 2008 and were installed in nearly every tobacco vending machine by July 2008 across the nation. ${ }^{26}$ Furthermore, these events were reported in the mass media. This might have resulted in the significantly high cessation rates in 2005-2006 and 2007-2008.

Differential effects of the tobacco price increase in various subgroups were observed for both cessation and relapse. Previous studies have reported that tobacco price increases promote cessation and prevent relapse more among the poor than among the affluent. ${ }^{1} 910$ However, this study did not support this association for cessation, that is, significantly positive AORs for cessation were observed among all income subgroups with no large difference in point estimate. This was in 
line with a previous study ${ }^{23}$ and confirmed by an additional result that no significant interaction term between year and income was found in the GEE analyses for cessation. As for relapse, when the tobacco price increased, it was only significantly associated with prevention of relapse in the lowest income subgroup (figure 2).

Further, we observed no effect modification of the price increase on either cessation or relapse by sex in this study (figures 1 and 2), which is in line with the results from a review paper that reported no clear evidence for differential effects by sex. ${ }^{9}$ This is possibly because this study did not include the younger generation who are likely to stop smoking when specific events occur such as pregnancy or childcare. ${ }^{27}$ As for number of cigarettes smoked per day, the price increase was not significantly associated with increased cessation in the subgroup of heavy smokers (31 or more cigarettes smoked per day), although the point estimate was positive. In all other subgroups of fewer cigarettes smoked per day, the price increase was significantly associated with cessation (figure 1).

Interestingly, differential impacts of the price increase on relapse were observed according to baseline characteristics such as recent quitter or long-term quitter, level of household income and self-rated health. Consistent with previous studies, ${ }^{28}$ recent quitters were more likely to relapse than long-term quitters. However, we found that, when the price increased (figure 2), it was significantly associated with prevention of relapse among recent quitters; the same was not true for long-term quitters, although the relapse rate among recent quitters was high, even in 2009-2010 (15.0\%). Similarly, quitters with very poor selfrated health had a significantly higher association with relapse than those with excellent health. When the price increased, it was only significantly associated with prevention of relapse in the very poor health subgroup, although point estimates of $<1 \mathrm{AOR}$ were observed in all other health subgroups. Taken together, our findings suggest the existence of several high-risk subgroups (eg, heavy smoker and short-term quitter) for tobacco control.

\section{Policy implications}

During the period 2009-2010, smoking prevalence decreased (from 27.2\% to 24.5\%) at the same time as the 2010 tobacco price increase. However, in 2011, there was a slight increase to $25.1 \%$. The notion of 'hardening' among smokers must also be taken into consideration. After some smokers who were less dependent and found it easier to quit have done so, the remaining smokers may become less likely to quit over time, that is, hardening. ${ }^{20}$ However, since the trend of the period was not significant for either cessation or relapse in both weighted and unweighted analyses, no evidence of a hardening in smokers was obtained. The entire distribution of smoking volume shifted down over time (table 1). This might be a key step in moving towards cessation. Although this study did not investigate longterm cessation, it is important to determine whether smokers successfully quit in the long term or not. Further studies to investigate long-term changes including cessation or reduction in the number of cigarettes smoked per day will be required in the future.

In recent years, the price of tobacco in Japan has been considered very low according to the affordability index. ${ }^{29}$ Cigarettes were more affordable in Japan than in any other developed countries surveyed in 2009; the price of a pack of 20 cigarettes could be earned in 11.5 min compared with $30 \mathrm{~min}$ in many other countries. ${ }^{29}$ After the 2010 price increase, this figure rose slightly (to around $16 \mathrm{~min}$ ) but remained low compared with other countries.
Our current findings suggest that we need to consider the stages of tobacco control policy in Japan. The early stages of public health interventions, such as health information campaigns, often cause health equity problems. ${ }^{30}$ The inverse equity bypothesis $^{31}$ avers that such interventions disproportionately benefit the wealthy, so there is an initial increase in inequality (early stage). Deprived sections of society catch up after the affluent have gained maximum benefit (late stage). Although the tobacco price increased in 2010 in Japan, the low price may mean that the 'early stage' of the tobacco price intervention will continue. Further price increases may thus be necessary to alleviate health inequalities.

In the Japanese health promotion strategy, Health Japan 21 (Second version), government ask for reduction of both smoking prevalence and health in equality (including smoking inequality). ${ }^{32}$ This study identified high-risk populations for tobacco control, that is, groups that are less sensitive to tobacco price increase, although they may respond to further higher tobacco price increases. Since some subgroups are less likely to quit smoking or continue to not smoke, even if the tobacco price is increased by up to $37 \%$, and furthermore respond slowly to price increases, additional tobacco control measures targeting the high-risk subgroups may be required.

\section{Limitations}

There are several limitations to the study. First, the smoking variables were self-reported without biomarker validation; however, the quality of the self-reporting was generally high. $^{33} 34$ Second, unmeasured factors such as tax avoidance and product substitution based on a wide price range may have biased the estimated effect. ${ }^{135}$ However, tax avoidance is likely to be low in this setting; Japan's island nation status makes it difficult to avoid tax across national borders. Although lowprice tobacco products (eg, the cheap Echo brand) gained market share in Japan after 2010, according to the tobacco industry's reports, ${ }^{36}$ the increase was small $(0.5 \%$ from 2010 to 2011). Therefore, the impact of product substitution may be trivial. Third, we considered the income of the respondents and their spouses, if available, since the income of other family members could not be obtained from the survey. It should be noted that household income, as defined in this study, probably underestimated household income. ${ }^{15}$

\section{What this paper adds}

\section{What is already known on this topic?}

- The impact of tobacco price increases on smoking behaviour in different social groups has been investigated; mixed results have been reported for differences in gender, occupation and education subgroups.

- Since few previous studies focused on the impact of price on relapse, longitudinal studies that have examined the effect of tobacco price on both cessation and relapse are scarce.

What this study adds?

- Of all the factors surveyed, only the tobacco price increase in 2010 was significantly associated with cessation (100\% increase) and relapse (40\% decrease).

- The tobacco price rise was associated with favourable smoking changes in nearly all population subgroups. 


\section{CONCLUSION}

Since recent quitters are likely to relapse, ${ }^{6} 28$ it is important to enhance both promotion of cessation and prevention of relapse. We confirmed that tobacco price rises were significantly associated with increasing cessation among smokers and decreasing relapse among quitters concurrently. ${ }^{1}$ Furthermore, this price rise was associated with favourable smoking changes in nearly all population subgroups; a large differential impact was not observed across the various subgroups.

Acknowledgements The authors thank Dr J Mortimer for her English language editing.

Contributors TT conceptualised and designed the study, drafted the initial manuscript and revised it, and approved the final manuscript as submitted. TF and TS supervised the data analyses, reviewed and revised the manuscript, and approved the final manuscript as submitted.

Funding This work was supported by the Ministry of Health, Labour and Welfare (grant; Comprehensive Research on Life-Style Related Diseases including Cardiovascular Diseases and Diabetes Mellitus (H25-010)) and the Ministry of Education, Culture, Sports, Science, and Technology (grant-in-aid for Young Scientists B: number 15K19256).

Competing interests None declared.

Provenance and peer review Not commissioned; externally peer reviewed.

Data sharing statement The Ministry of Health, Labour and Welfare, Japan, does not make all the raw data publicly available. However, data are available on request under the 33th article of the Japanese Statistical Law, at Examination Analysis Office, Planning Division, the Statistics and Information Department, Minister's Secretariat, the Ministry of Health, Labour and Welfare, Japan.

Open Access This is an Open Access article distributed in accordance with the Creative Commons Attribution Non Commercial (CC BY-NC 4.0) license, which permits others to distribute, remix, adapt, build upon this work non-commercially, and license their derivative works on different terms, provided the original work is properly cited and the use is non-commercial. See: http://creativecommons.org/ licenses/by-nc/4.0/

\section{REFERENCES}

1 International Agency for Research on Cancer. IARC handbooks of cancer prevention tobacco control volume 14: effectiveness of tax and price policies for tobacco control. Lyon, France: WHO Press, 2011.

2 Eriksen M, Mackay J, Schluger N, et al. The Tobacco Atlas, fifth edition: revised, expanded, and updated. Atlanta, USA: American Cancer Society, 2015.

3 International Agency for Research on Cancer. IARC handbooks of cancer prevention tobacco control volume 13: evaluating the effectiveness of smoke-free policies. Lyon, France: WHO Press, 2009.

4 Ross $\mathrm{H}$, Blecher $\mathrm{E}$, Yan L, et al. Do cigarette prices motivate smokers to quit? New evidence from the ITC survey. Addiction 2011;106:609-19.

5 Dunlop SM, Perez D, Cotter T. Australian smokers' and recent quitters' responses to the increasing price of cigarettes in the context of a tobacco tax increase. Addiction 2011;106:1687-95.

6 Wakefield MA, Bowe SJ, Durkin SJ, et al. Does tobacco-control mass media campaign exposure prevent relapse among recent quitters? Nicotine Tob Res 2013;15:385-92.

7 Tauras JA. Public policy and smoking cessation among young adults in the United States. Health Policy 2004;68:321-32.

8 Amos A, Greaves L, Nichter M, et al. Women and tobacco: a call for including gender in tobacco control research, policy and practice. Tob Control 2012;21:236-43.

9 Thomas S, Fayter D, Misso K, et al. Population tobacco control interventions and their effects on social inequalities in smoking: systematic review. Tob Control 2008; 17:230-7.

10 Hill S, Amos A, Clifford D, et al. Impact of tobacco control interventions on socioeconomic inequalities in smoking: review of the evidence. Tob Control 2014;23(e2):e89-97.
11 Ito $Y$, Nakamura M. The effect of increasing tobacco tax on tobacco sales in Japan. Jpn J Public health 2013;60:613-18. (in Japanese).

12 Ministry of Health, Labour and Welfare. Comprehensive survey of living condition of people on health and welfare. Tokyo, 2014. http://www.mhlw.go.jp/toukei/list/2021.html (accessed 1 Nov 2015) (in Japanese)

13 Ministry of Health, Labour and Welfare. Longitudinal survey of middle-aged and elderly persons. Tokyo, 2014. http://www.mhlw.go.jp/toukei/list/29-6.html (accessed 1 Nov 2015) (in Japanese)

14 Oshio T. The association between involvement in family caregiving and mental health among middle-aged adults in Japan. Soc Sci Med 2014;115:121-9.

15 Kachi Y, Otsuka T, Kawada T. Precarious employment and the risk of serious psychological distress: a population-based cohort study in Japan. Scand J Work Environ Health 2014:40:465-72.

16 Organization for Economic Cooperation and Development (OECD). Growing unequal? Income distribution and poverty in OECD countries. Paris: OECD, 2008

17 Nishi N, Nakade M, Sarukura N, et al. Response rate and the related factors of National Health and Nutritional Survey. Kosei no Shihyo 2012;59:10-15. (in Japanese).

18 Little RJ, D'Agostino R, Cohen ML, et al. The prevention and treatment of missing data in clinical trials. N Engl J Med 2012;367:1355-60.

19 Hanley JA, Negassa A, Edwardes MD, et al. Statistical analysis of correlated data using generalized estimating equations: an orientation. Am J Epidemiol 2003:157:364-75.

20 Docherty $G$, McNeill A, Gartner $C$, et al. Did hardening occur among smokers in England from 2000 to 2010? Addiction 2014;109:147-54.

21 Katanoda K, Jiang Y, Park S, et al. Tobacco control challenges in East Asia: proposals for change in the world's largest epidemic region. Tob Control 2014;23:359-68.

22 Abadie A, Diamond A, Hainmueller J. Synthetic control methods for comparative case studies: estimating the effect of California's tobacco control program. J Am Stat Assoc 2010;105:493-505.

23 Tabuchi T, Nakamura M, Nakayama T, et al. Tobacco price increase and smoking cessation in Japan, a developed country with affordable tobacco: a national population-based observational study. J Epidemiol 2016;26:14-21.

24 Pfizer Japan Inc. Internet survey for Japanese smokers before tobacco tax increase in 2010. Japan: Pfizer Japan Inc, 2010.

25 Nakamura M, Oshima A, Ohkura M, et al. Predictors of lapse and relapse to smoking in successful quitters in a varenicline post hoc analysis in Japanese smokers. Clin Ther 2014;36:918-27.

26 Kanda $H$, Osaki $Y$, Ohida $T$, et al. Age verification cards fail to fully prevent minors from accessing tobacco products. Tob Control 2011;20:163-5.

27 Tabuchi T, Fujiwara T. Are secondhand smoke-related diseases of children associated with parental smoking cessation? Determinants of parental smoking cessation in a population-based cohort study. Prev Med 2015;73:81-7.

28 Hughes JR, Keely J, Naud S. Shape of the relapse curve and long-term abstinence among untreated smokers. Addiction 2004;99:29-38.

29 Eriksen M, Mackay J, Ross H. The tobacco Atlas. 4th edn. Atlanta, USA: American Cancer Society, 2012.

30 Frohlich KL, Potvin L. Transcending the known in public health practice: the inequality paradox: the population approach and vulnerable populations. Am J Public Health 2008:98:216-21.

31 Victora CG, Vaughan JP, Barros FC, et al. Explaining trends in inequities: evidence from Brazilian child health studies. Lancet 2000;356:1093-8.

32 Ministry of Health, Labour and Welfare. Health Japan 21 (Second). 2012. http:// www.mhlw.go.jp/bunya/kenkou/kenkounippon21.html (accessed 1 Nov 2015) (in Japanese)

33 Ministry of Health, Labour and Welfare. National Health and Nutritional Survey 2003. Tokyo, 2005. http://www.mhlw.go.jp/bunya/kenkou/eiyou-chosa2-01/index. $\mathrm{html}$ (accessed 1 Nov 2015) (in Japanese)

34 Caraballo RS, Giovino GA, Pechacek TF, et al. Factors associated with discrepancies between self-reports on cigarette smoking and measured serum cotinine levels among persons aged 17 years or older: third National Health and Nutrition Examination Survey, 1988-1994. Am J Epidemiol 2001;153:807-14.

35 Wilson LM, Avila Tang E, Chander G, et al. Impact of tobacco control interventions on smoking initiation, cessation, and prevalence: a systematic review. J Environ Public Health 2012;2012:961724.

36 Tobacco Institute of Japan. Cigarette statistics in Japan. Tokyo, 2013. http://www. tioj.or.jp/data/index.html (accessed 1 Nov 2015) (in Japanese) 